\title{
Modeling Urban Freight Generation: A Study of Commercial Establishments' Freight Needs
}

\author{
Iván Sánchez-Díaz, Ph.D. \\ Senior Lecturer, Department of Technology Management and Economics \\ Chalmers University of Technology, Vera Sandbergs Allé 8, Göteborg, 41296, Sweden, Email: \\ ivan.sanchez@chalmers.se
}

\begin{abstract}
Increasing urbanization, and the environmental and liveability impacts associated with urban activity, have directed attention to the need for sustainable cities. Achieving sustainable urban development requires including freight systems in strategic urban development plans. In this context, joint efforts involving academia and public- and private sector to collect the right data and develop suitable models, can contribute toward a better understanding of establishments' freight needs, the quantification of freight's traffic impacts and the development of appropriate methods to support decision making and strategic plans. This paper studies urban commercial establishments' freight needs and impacts on traffic using data collected from establishments in the City of Gothenburg (Sweden). The data cover different zones of the city and include commercial sectors found typically in urban cores (e.g., retailers, food services, health care, public sector offices and education). The paper introduces a set of statistical models-developed based on regression analyses and discrete choice models - to estimate the number of freight trips produced and attracted per week, and the attraction of weight and volumes of freight. In addition to shed light on the factors determining establishments' freight- and freight trips generation, the models are designed with the purpose of assisting planning and policy design efforts, thus the explanatory variables are selected based on suitability and availability. The results show that retailers of perishable goods have the highest freight trip generation per establishment, followed by public sector offices and education establishments, retailers of non-perishable goods and restaurants. The results also reveal a heterogeneity between sectors, and a differential business size effect across commercial sectors.
\end{abstract}

Keywords: Freight Trip Generation, Freight Generation, Freight Attraction, Urban Freight, Freight Demand Modeling, Receivers' behavior

\section{INTRODUCTION}

During the last decades, the world has seen a rapid growth of an urban population with an increasing access to global supplies. While in 1950 only one-third of the global population lived in urban environments, this proportion reached half of the population in 2014, and is expected to grow to two-thirds by 2050. In absolute terms, this means that urban environments hosted 746 million dwellers in 1950, 3.9 billion in 2014 and are expected to host 6.4 billion in 2050 [1]. This growth raises several concerns as cities already generate more than $80 \%$ of the global gross domestic product (GDP), consume two-thirds of the world's energy, and produce more than $70 \%$ of global greenhouse gas emissions [2]. Not surprisingly, this situation has intensified global efforts to align policy, planning and investment choices in a way that favors efficient, inclusive, safe, resilient and sustainable cities. 
Urban planners, researchers and policy makers have identified some elements—such as increasing walkable spaces, mixing land-uses, increasing urban density, promoting the use of public transportation, and fostering cleaner vehicle technologies, among others - that can be instrumental in this quest [3]. The passenger transportation system has progressively been adapted to cope with this new reality by increasing access to public transportation, decreasing parking space for cars, implementing congestion charges, integrating transportation and land-use plans, among other initiatives. However, in the case of freight, public interventions have been limited to a few measures that have often not being effective or even generated counterproductive effects (e.g., access restrictions based on time of the day, load factor, vehicle size; congestion charging; urban consolidation centers) [4]. In this context, there is a pressing need for the freight transportation research community to find ways to smooth the access of goods to citizens without hampering the city's livability.

One of the reasons explaining the unsatisfactory results from initiatives aimed at improving freight movements' efficiency is the lack of knowledge about the urban freight system and the behavior of freight agents, as well as the deficient quantification of the problem. Hence, the efforts to collect quality data and develop urban freight models are bound to improve the knowledge of the system, to facilitate the formulation of suitable initiatives and to enhance the public sector's decision making process. A step in this direction is to study urban establishments' freight needs and the traffic generation that these needs entail, which can be done through the collection of Freight Generation (FG) and Freight Trip Generation (FTG) data, and the development of quantitative models.

FG can be defined as the physical expression of the flows from economic exchanges (i.e., goods exchanged for money between two economic agents) which can be quantified in terms of weight, value, or volume; while FTG denotes the amount of freight vehicles (i.e., traffic) that are required to transport the FG [5, 6]. In suburban areas, FG is mainly a consequence of large scale operations (e.g., manufacturing, wholesale, warehousing and logistic operations) that results into high FG per establishment. In central urban environments, the focus of this paper, FG is mainly a consequence of commercial activities that serve final consumers (e.g., food services, retailers, schools, hospitals, offices), resulting into numerous establishments with relatively small — compared to sub-urban areas-FG per establishment. However, when added together these establishments require a substantial amount of freight that needs to be transported in an efficient way to reach the final destination with minimum impacts to the city.

It is important to study both FTG and FG because FTG quantification is crucial to assess the traffic impacts of different activities and evaluate potential savings of novel initiatives, and FG quantification is key to design and evaluate the feasibility of those initiatives. For instance, FTG models can be used to assess potential traffic impacts savings from a consolidation center; but a FG analysis is necessary to identify whether an establishment's freight needs can be fulfilled through a consolidation center, the type and amount of vehicles that would be necessary, and the space needs for the consolidation facility.

This paper is organized in four sections in addition to this introduction. Section 2 provides a background on the concepts of FG and FTG and provides a discussion of the relevant literature. Section 3 describes the methodology followed for this study. Section 4 presents the results, and Section 5 discusses the conclusions from this research.

\section{BACKGROUND}

In line with the generic terminology used for demand models, the term generation encompasses both production and attraction [7]. Urban establishments have a Freight Attraction (FA) that depends on the intensity of their 
economic activity; and a Freight Trip Attraction (FTA) that depends on (i) their FA, (ii) the variety of supplies required for their type of activity, and (iii) their ordering policy [5, 8]. The role of the shipper and the carrier is typically to select a shipment size and a vehicle type that meet the receivers' requests while maximizing their own benefits. Central urban establishments' Freight Trip Production (FTP) tends to be smaller than in suburban establishments because most goods are consumed in place or brought home by the final consumers through personal transportation modes.

Although during the last two decades the interest on freight demand modeling has significantly increased, the body of literature studying FG and FTG is still small. The main reasons are the lack of establishment-based data and the complexity of modeling the heterogeneous behavior of firms. Some authors have attempted to counter this difficulty through the use of traffic counts and disaggregating data from regional models [9, 10]. However, these secondary sources of information are complementary but cannot replace the data from shippers and receivers because the latter provide the connection between FG/FTG and the underlying economic activity, which offer key insights for planning and public policy development. Table 1 summarizes the different sources of data for FTG and local traffic analysis and their advantages and disadvantages.

Table 1: Data sources for FTG and local traffic analysis: advantages and disadvantages

\begin{tabular}{|c|c|c|}
\hline Data source & Main advantages & Main disadvantages \\
\hline Traffic counts & -Simple to measure and estimate & $\begin{array}{l}\text {-Freight trips not linked to establishments } \\
\text {-Little insight into causality: role of logistics disregarded } \\
\text {-Limited use for policy analysis }\end{array}$ \\
\hline $\begin{array}{l}\text { Secondary } \\
\text { sources: } \\
\text { aggregated } \\
\text { data }\end{array}$ & $\begin{array}{l}\text {-Limited data collection efforts } \\
\text {-Low cost }\end{array}$ & $\begin{array}{l}\text {-Freight trips not linked to establishments } \\
\text {-Little insight into causality: role of logistics disregarded } \\
\text {-Limited use for policy analysis } \\
\text {-Disaggregation techniques assume employment } \\
\text { proportionality } \\
\text {-Trips within zones are not considered } \\
\text {-Often limited to heavy commercial vehicles (>3 tons) }\end{array}$ \\
\hline $\begin{array}{l}\text { Transport } \\
\text { operators' data }\end{array}$ & -High detail about shipment size & $\begin{array}{l}\text {-Estimates per establishment are partial (not all operators } \\
\text { interviewed) } \\
\text {-Little insight into causality: role of logistics disregarded } \\
\text {-Freight trips not linked to establishments } \\
\text {-Limited use for policy analysis }\end{array}$ \\
\hline $\begin{array}{l}\text { Establishment- } \\
\text { based surveys }\end{array}$ & $\begin{array}{l}\text {-Estimates at establishment level } \\
\text {-Connects FTG to establishment attributes } \\
\text {-Allow forecasting and policy analysis } \\
\text {-Allow aggregation at any geographical } \\
\text { level }\end{array}$ & $\begin{array}{l}\text {-Higher cost } \\
\text {-Require cooperation from commercial establishments } \\
\text {-Require modeling efforts } \\
\text {-Limited knowledge about routes and vehicles } \\
\text {-Do not capture through traffic }\end{array}$ \\
\hline
\end{tabular}

The FTG literature includes a number of reports that compile models from different sources or estimate their own statistical models [6, 9, 11-13]. The Quick Response Freight Manual II [13], for instance, uses the data collected from a freight origin-destination study in Phoenix (Arizona) to estimate FTG rates for different truck 
types based on employment. The Institute of Transportation Engineers (ITE) Trip Generation Manual, one of the most popular manuals for passenger trip generation, is a compilation of trip generation studies submitted by public agencies, consulting firms, and universities, for which FTG is estimated as a proportion of passenger trips [9]. The NCFRP 25 Freight Trip Generation and Land Use Report [6] presents a comprehensive discussion on FTG modeling, as well as a set of case studies with establishments-based FTG models in NYC and other northeastern states in the US. The authors estimate FTG models for different industry and land-use classification systems, different functional forms and estimation techniques, i.e., trip rates, ordinary least squares (OLS) and multiple classification analysis (MCA).

In addition to these compilations, there are a number of publications that introduce urban FTG models. Most of them are based on land-use and industry classification systems, and use business size as independent variables. For instance, Bartlett and Newton [14] use employment and area to estimate FTG models for a wide range of industry sectors. Ramakrishna and Balbach [10] estimate land-use based FTG models in California, where FTG is differentiated by type of vehicle and is based on traffic counts. Iding, et al. [15] estimate a set of FTG models for The Netherlands based on the number of employees and company area. The FTG estimations at the establishment level by Routhier and Toilier [16] are used as an input for FRETURB, a French urban freight demand model. Kawamura, et al. [17] propose a set of FTG models based on employment and area using data from 5 furniture chains and 4 shoe chains across Midwestern US states. Using data from New York City (NYC), Bastida and Holguín-Veras [18] show that the type of commodity handled by establishments is an important factor determining FTG.

Holguín-Veras, et al. [5] explain the differences between FG and FTG, and show that FG and FTG should be studied separately because, while FG is the result of the economic activity taking place at the establishment, FTG is the result of the logistic decisions to transport the FG (e.g., shipment size, frequency). In terms of modeling, the authors propose to use differentiated functional forms to replicate the role of logistical decision on FTG. Campbell, et al. [19] study the implications of using two different industry classifications systems for FTG and suggest that the old Standard Industry Classification system may be more appropriate to model FTG. Lawson, et al. [20] implement OLS and MCA to estimate FTG models for different land-uses based on local and national classification standards. The transferability of FTG across cities is assessed by Holguín-Veras, et al. [21], who conclude that the FTG models proposed are applicable to different cities across the US. Jaller, et al. [22] propose a set of area-based FTG models. Sánchez-Díaz, et al. [23] show the importance of studying FTA and FTP separately because they are driven by different factors, and explores the nonlinear relationship between FTA and employment. The authors also explore the spatial autocorrelation and locational effects on FTA, and conclude that incorporating locational variables, such as land-value and width of the front street, can enhance the performance of FTA models. Jaller, et al. [24] discuss the importance of identifying urban freight intermediaries (i.e., establishments that both attract and produce trips) to estimate FTP accurately, as applying FTP models without distinguishing pure receivers from intermediaries will lead to an overestimation of FTG. González-Feliu, et al. [25] present a set of FTP models calibrated with data from Bordeaux (France). Alho and de Abreu e Silva [26] present the results from a retail establishment-based survey in Lisbon and estimate a set of employment and area based models. The authors find that employment models perform better than area models, and that these type of models have a low predictive power. Ducret and Gonzalez-Feliu [27] propose a dispersion analysis for FTG at the establishment level; and Gonzalez-Feliu, et al. [28] study the modeling implications of using different levels of detail in the industry classification system. The authors show that some industry sectors have higher heterogeneity. In particular, some sub-sectors within the manufacturing and the 
retail sectors present a FTA pattern that differ from the overall industry group, so that a more detailed segmentation within those groups will lead to more accurate estimations.

In contrast to the recent growth in FTG research, the development of FG models at the urban level is practically unexplored. Urban FG estimates are often obtained from aggregate models and input-output analysis to distribute FG among zones and commodities [29-31]. For instance, Russo and Comi [31] propose an aggregate method for Reggio Calabria (Italy) to estimate FA as a rate of the number of families and the number of retailers living within the area of study. In some cases, input-models and make/use tables are used to connect production factors to the activity of each sector through production-consumption links [32, 33]. Guldbrand, et al. [34] present the results from a data collection effort to measure FG in terms of weight and volume; this paper uses the data collected and builds on the models developed by Guldbrand, et al. [34].

As shown in this literature review, urban FG and FTG models are still in their early stage of development. The author identified a concerning lack of FG studies for urban establishments which prevents from having a clear picture of the weight and volume of the freight that is transported into urban environments. This paper seeks to improve the knowledge on FG and FTG through a data collection exercise and a statistical modeling approach. In this research FG and FTG data are collected from establishments located in the City of Gothenburg (Sweden); these data are then used to estimate practice-ready econometric models to quantify FG and FTG.

\section{METHODOLOGY}

This section describes the methodology followed to develop the FG and FTG models introduced in this paper. The first part describes the process followed to collect the data for the City of Gothenburg. The second part describes the process followed to estimate the models.

\subsection{Data collection framework}

The sample was designed using a stratified sampling to cover the City of Gothenburg and ensure the presence of establishments in commercial sectors typically present in urban environments: retailers, restaurants, cafés, offices, schools, hospitals and other service activities (sub-urban activities, such as manufacturing and wholesaling were out of the scope of this study). The Swedish Standard Industrial Classification (SNI) was used to define groups of establishments that have similar commercial activities and for which similar logistics decisions are made; similar FG/FTG patterns should thus be expected within each group [35]. The commercial sectors selected were grouped as retail of perishable products, such as retail of food, beverages, flowers, plants, seeds, and tobacco (SNI codes: G-4711, G-472, G-4776, G-4781, G-47992); retail of non-perishable products, such as information and communication equipment, household equipment, cultural and recreation goods, clothing, footwear, watches and jewelry, among others (SNI codes: G-4719, G-473 to G-476, G-4771 to G4775, G-4777 to G-4779, G-4782, G-4789 and G-479), food services, such as cafés, restaurants and pubs (SNI code I-56), health care and other wellbeing services, such as hospitals and hair saloons (SNI codes: Q-86 and S-9602), public sector offices and education (SNI codes: O and P), and other offices, such as publishing activities, programming and broadcasting, financial services and real state among others (SNI codes: K, L, M, and N). Using the SNI codes allows to use secondary data from official statistics. The number of establishments in Gothenburg Municipality for each of these commercial sectors is shown in Table 2. As shown, most of the establishments are offices, followed by health care services, retail of non-perishable goods, public services and education, accommodation and food, and retail of perishable goods. 
Table 2: Number of establishments from the selected commercial sectors in the study area from the Swedish Central Office of Statistics (SCB)

\begin{tabular}{|l|r|r|}
\hline \multicolumn{1}{|c|}{ Commerical sector } & Establishments & \multicolumn{1}{c|}{ Share } \\
\hline Offices & 6,904 & $44.0 \%$ \\
\hline Retail non-perishable & 3,136 & $20.0 \%$ \\
\hline Accommodation and Food & 2,212 & $14.1 \%$ \\
\hline Public services and education & 1,290 & $8.2 \%$ \\
\hline Health care services & 1,096 & $7.0 \%$ \\
\hline Retail perishable & 1,038 & $6.6 \%$ \\
\hline Total & 15,676 & $100.0 \%$ \\
\hline
\end{tabular}

Note: Offices and establishments in the public services, education, health care services that reported 0 employees were not considered. The shares do not consider other sectors present in the zone (e.g., manufacturing, wholesale), but not selected for the study.

The data collection was designed with a mail-in mail-out questionnaire complemented by a number of calls and interviews in situ. The data collection in situ was used to increase the response rate and to collect additional information related to FG. The data collection took place between 2014 and 2015, resulting in 195 observations from the different commercial sectors. The overall response rate - excluding offices — was 39.8\%; although the real response rate (i.e., when considering only establishments in the sample that are currently in business) may actually be higher because an important share of non-responses were undelivered returned envelopes and failed calls for establishments with incorrect contact information. For establishments interviewed in situ, the response rate was $86 \%$.

The questionnaire inquired about the number of delivery trips attracted (i.e., FTA) and the number of outgoing trips (i.e, FTP) produced by the establishment on a typical week, the amount of cargo attracted to the establishment (i.e., FA), the delivery units (e.g., pallet, parcel), the type of vehicles delivering freight, the number of suppliers, the number of employees, the establishment area, and the ordering and stockholding policy, among others. Not every observation has data for all the questions.

As mentioned before, FA can be measured in different units, such as weight and volume. However, obtaining FA data from establishments is a challenging task, because most receivers do not weight or measure the freight they receive. To overcome this challenge, the questionnaire inquires for Freight Weight Attracted (FWA) using ranges (i.e., 0-10 kg, $11-50 \mathrm{~kg}, 51-100 \mathrm{~kg}, 101-500 \mathrm{~kg}, 501-1,000 \mathrm{~kg}$, or more than 1,000 kg per week) which is more convenient for the respondent. Additionally, one of the sectors was selected to visit the respondents and measure the Freight Volume Attracted (FVA) in a typical week. Establishments in the perishable retail sector were selected for the interviews in situ and the FVA study because the literature shows its relevance to implement sustainable urban freight initiatives [8, 36, 37].

\subsection{Model development}

The methodology proposed seeks to provide technically sound FG and FTG models that can be used to quantify freight needs and traffic impacts generated by commercial establishments. These models also shed light on the empirical relationship between FG/FTG and some explanatory variables, such as, employment, area, and commercial sector. Although there are other variables that could be useful to improve the explanatory power of the models (e.g., sales, commodity type and size, storage space, waste), this paper focuses on variables that capture commercial establishments' needs and preferences, but that can be used for public sector planning and 
policy development purposes for which the amount of available information is limited (e.g., planned area, expected employment, type of commercial activity). Based on the literature review, the key premises for the model development are that $(i)$ the size of an establishment (measured in area or employment) is a good indicator of its commercial activity intensity, so that larger establishments require larger FG to operate, (ii) establishments in different commercial sectors have different logistics needs and thus have different ordering/ stockholding preferences, and (iii) as FTG depend on both the FG and the ordering policy, FTG is not necessarily directly proportional to business size.

This section assumes that establishments' decision makers take into consideration only their establishments' needs (although in reality they can also be affected by their personal attributes or preferences). For this reason the term commercial establishment or simply establishment is used to denote the decision maker. The model development uses the cross-sectional data collected to estimate $(a)$ econometric models in which the pooled data include observations (i.e., establishments) from different commercial sectors and ( $b$ ) econometric models in which one model is estimated for each commercial sector. One advantage of using type (a) models is that the model has more degrees of freedom because commercial sectors are not segmented unless the difference is statistically significant. However, using type $(a)$ models implies that there is a certain homogeneity across establishments even if they belong to different commercial sectors, which is an assumption the practitioner may prefer not to make. This paper presents the results from the two types of models.

FTP models are estimated using discrete-continuous models, which require two steps [24, 38]. The first step is a binary logit or probit model that identifies establishments that act as freight intermediaries (i.e., produce freight trips); this step is particularly important to avoid overestimation for establishments located in urban cores where a large share do not have any FTP. The binary logit / probit of the first step uses random utility theory to estimate the probability that an establishment is an intermediary [7, 39]. An establishment's utility is, thus, expressed as a linear function of its attributes as follows:

$$
U_{n}=\alpha+\lambda \boldsymbol{\delta}_{n}+\boldsymbol{\beta} \mathbf{X}_{n}+\boldsymbol{\theta} \boldsymbol{\delta}_{n} \mathbf{X}_{n}+\eta_{n}
$$

Where,

$U_{n}$ : The utility function for establishment $n$

$\alpha$ : The intercept

$\lambda$ : A vector of estimable parameters for the binary variables

$\boldsymbol{\delta}_{\mathbf{n}}$ : A vector of binary variables denoting the commercial sector of establishment $n$; each binary variable denotes a sector and takes the value of 1 if establishment $n$ belongs to the sector, 0 if not.

$\boldsymbol{\beta}$ : A vector of estimable parameters

$\mathbf{X}_{\mathbf{n}}$ : A vector of continuous variables or attributes proper to establishment $n$

$\boldsymbol{\theta}:$ A vector of estimable parameters

$\eta_{n}:$ A random disturbance

In the case of a logit model, the random disturbance $(\eta)$ is assumed to follow a Gumble distribution. Thus, the probability that an establishment is an intermediary is computed as follows:

$$
P\left(\gamma_{n}=1\right)=\frac{\exp \left(U_{n}\right)}{1+\exp \left(U_{n}\right)}
$$

Where,

$\gamma_{n}$ : A binary variable that takes the value of 1 if establishment $n$ is an intermediary, and 0 if not. 
For the second step of FTP models, as well as for FTA and FVA models, the dependent variable is a continuous variable (trips per week, delivery trips per week and cubic meters per week, respectively) that can be estimated using regression analysis. The generic form of the FTA, FTP and FVA models is presented in equation (1):

$$
Y_{n}=\alpha+\lambda \boldsymbol{\delta}_{n}+\boldsymbol{\beta} \mathbf{X}_{n}+\boldsymbol{\theta} \boldsymbol{\delta}_{n} \mathbf{X}_{n}+\varepsilon_{n}
$$

Where,

$Y_{\mathrm{n}}$ : A continuous dependent variable for establishment $n$

$\varepsilon_{n}$ : A random disturbance term, $\varepsilon$ assumed to follow a normal distribution with mean 0 and variance $\sigma^{2}$.

The other terms are as defined for equation (1).

The model parameters are estimated using robust variance estimates, or sandwich estimators, that account for the correlations in the error terms and are robust to specification errors and outliers [40]. For the models of type (b), each commercial sector is studied separately, thus no binary variables or their parameters are necessary. The functional specification is determined based on a conceptual analysis, a statistical significance analysisonly variables significant at the 5\% level are included — and the models' Root Mean Square Error (RMSE).

Modeling FWA requires a discrete choice model because the dependent variable $\left(Z_{n}\right)$ is an ordinal variable that denotes the level of FWA intensity: $Z_{n}=1$ if FWA is between 0 and $10 \mathrm{~kg}, Z_{n}=2$ if FWA is between 11 and $50 \mathrm{~kg}, Z_{n}=3$ if FWA is between 51 and $100 \mathrm{~kg}, Z_{n}=4$ if FWA is between 101 and $500 \mathrm{~kg}, Z_{n}=5$ if FWA is between 501 and $1,000 \mathrm{~kg}$, and $Z_{n}=6$ if FWA is more than $1,000 \mathrm{~kg}$ per week. The most appropriate models for this structure are the ordered logit and probit, in which the dependent variable is estimated using simultaneously a utility function and a set of thresholds $(\mu)$ that segment the range of the utility function to reproduce the choice probabilities from the calibration data. Based on the postulates from the random utility theory, individuals-in this case establishments - can be assumed to act rationally and select the alternative that maximizes their utility; and the utility can be represented as a linear function of attributes of the establishments and their available alternatives [7, 39]. The utility function can, thus, be represented as in equation (1), and the set of thresholds, $0<\mu(1)<\mu(j)<\mu(6)$, are estimated simultaneously with the utility function, such that:

$$
\begin{array}{lll}
Z_{n}=1, & \text { if } & U_{n} \leq 0 \\
Z_{n}=2, & \text { if } & 0<U_{n} \leq \mu(1) \\
Z_{n}=\mathrm{j}, & \text { if } & \mu(j-2)<U_{n} \leq \mu(j-1) \\
Z_{n}=6, & \text { if } & U_{n}>\mu(5)
\end{array}
$$

Where,

$Z_{n}$ : An ordinal dependent variable for establishment $n$.

This block of equations shows that a higher utility is associated with a higher level on the dependent variable. The parameters and the thresholds are estimated using a maximum likelihood approach, and the quality of the model can be measured through the highest log-likelihood value, and the likelihood ratio index (i.e., Pseudo R2) [39].

As the random disturbance term can be assumed to follow an independent and identically distributed (IID) Gumbel distribution, the probability for each level of $Z_{n}$ can be estimated using an ordered logit model, such that: 


$$
\begin{aligned}
P_{n}(1)=P\left(Z_{n}=1\right) & =\frac{1}{1+\exp \left(\alpha+\lambda \boldsymbol{\delta}_{n}+\boldsymbol{\beta}\left(1+\boldsymbol{\delta}_{n}\right) \mathbf{X}_{n}-0\right)} \\
P_{n}(j)=P\left(Z_{n}=j\right) & =\frac{1}{1+\exp \left(\alpha+\lambda \boldsymbol{\delta}_{n}+\boldsymbol{\beta}\left(1+\boldsymbol{\delta}_{n}\right) \mathbf{X}_{n}-\mu(j-1)\right)} \\
& -\frac{1}{1+\exp \left(\alpha+\lambda \boldsymbol{\delta}_{n}+\boldsymbol{\beta}\left(1+\boldsymbol{\delta}_{n}\right) \mathbf{X}_{n}-\mu(j-2)\right)} \\
P_{n}(6)=P\left(Z_{n}=6\right) & =1-\frac{1}{1+\exp \left(\alpha+\lambda \boldsymbol{\delta}_{n}+\boldsymbol{\beta}\left(1+\boldsymbol{\delta}_{n}\right) \mathbf{X}_{n}-\mu(5)\right)}
\end{aligned}
$$

After calibration, the model can be applied to estimate the level of FWA $\left(Z_{n}^{\text {est }}\right)$ using the following expression:

$$
Z_{n}^{e s t}=\sum_{j} P\left(Z_{n}=j\right) * j
$$

\section{RESULTS}

This section presents a summary of the data collected, including the descriptive statistics for the different variables, the results from the modeling efforts and a comparison between the FTG estimates and traffic counts.

\subsection{Data description}

The data collection efforts resulted into 195 observations, distributed as follows: 54 observations (27.7\%) in the retail perishable sector, 70 observations $(35.9 \%)$ in the retail non-perishable sector, 43 observations $(22.1 \%)$ in the food services sector, 8 observations $(4.1 \%)$ in the health care and other wellbeing services sectors, 7 observations (3.6\%) in the public sector offices and education sector, and 13 observations (6.6\%) from other offices. The offices sector was excluded from the FTG analysis because 9 of the 13 observations did not report any freight trips. As shown, the number of observations for the health care and other services, and the public sector and education is very limited. The results for those sectors are presented in this paper because there is limited information about these sectors' FTG in the literature; however, they should be used with caution. The descriptive statistics for the other sectors are presented in Table 3. 
Table 3: Summary statistics

\begin{tabular}{|l|l|r|r|r|r|r|}
\hline \multicolumn{7}{|c|}{ SNI: Retail perishable } \\
\hline \multicolumn{1}{|c|}{ Variable } & \multicolumn{1}{|c|}{ Unit } & Obs. & Mean & CV & Min & Max \\
\hline FTA & deliveries/week & 54 & 14.6 & $151 \%$ & 1 & 120 \\
\hline Intermediary & 1 if yes, 0 if not & 54 & 0.3 & $156 \%$ & 0 & 1 \\
\hline Interm. FTP & trips/week & 16 & 6.0 & $97 \%$ & 0 & 20 \\
\hline Employment & employees & 54 & 5.4 & $184 \%$ & 1 & 60 \\
\hline Area & $\mathrm{m} 2$ & 50 & 620.6 & $292 \%$ & 10 & 11,800 \\
\hline Storage & $\mathrm{m} 2$ & 44 & 147.1 & $285 \%$ & 1 & 2,700 \\
\hline FA_vol & $\mathrm{m} 3 /$ week & 32 & 72.7 & $263 \%$ & 1 & 914 \\
\hline
\end{tabular}

\begin{tabular}{|r|r|r|r|r|}
\hline \multicolumn{5}{|c|}{ SNI: Retail non-perishable } \\
\hline Obs. & Mean & CV & Min & Max \\
\hline 70 & 5.4 & $176 \%$ & 0 & 60 \\
\hline 70 & 0.6 & $82 \%$ & 0 & 1 \\
\hline 42 & 3.0 & $224 \%$ & 0 & 33 \\
\hline 70 & 2.9 & $70 \%$ & 1 & 9 \\
\hline 63 & 164.2 & $148 \%$ & 2 & 1,100 \\
\hline 18 & 172.1 & $185 \%$ & 0 & 1,100 \\
\hline n.a. & n.a. & n.a. & n.a. & n.a. \\
\hline
\end{tabular}

\begin{tabular}{|l|l|r|r|r|r|r|}
\hline \multicolumn{7}{|c|}{ SNI: Food services } \\
\hline \multicolumn{1}{|c|}{ Unit } & Obs. & Mean & \multicolumn{1}{c|}{ CV } & Min & Max \\
\hline FTA & \multicolumn{1}{|c|}{ Uniablies/week } & 43 & 5.1 & $92 \%$ & 0 & 20 \\
\hline Intermediary & 1 if yes, 0 if not & 43 & 0.5 & $99 \%$ & 0 & 1 \\
\hline Interm. FTP & trips/week & 22 & 3.4 & $177 \%$ & 0 & 26 \\
\hline Employment & employees & 43 & 4.9 & $89 \%$ & 1 & 18 \\
\hline Area & $\mathrm{m} 2$ & 32 & 100.2 & $61 \%$ & 20 & 250 \\
\hline Storage & $\mathrm{m} 2$ & 8 & 29.3 & $51 \%$ & 8 & 50 \\
\hline
\end{tabular}

\begin{tabular}{|r|r|r|r|r|}
\hline \multicolumn{5}{|c|}{ SNI: Health care, and other services } \\
\hline Obs. & Mean & CV & Min & Max \\
\hline 8 & 3.9 & $120 \%$ & 0 & 14 \\
\hline 8 & 0.8 & $62 \%$ & 0 & 1 \\
\hline 6 & 1.4 & $146 \%$ & 0 & 5 \\
\hline 8 & 9.3 & $216 \%$ & 0 & 59 \\
\hline 8 & 700.1 & $248 \%$ & 20 & 5,000 \\
\hline 4 & 33.8 & $132 \%$ & 7 & 100 \\
\hline
\end{tabular}

\begin{tabular}{|l|l|r|r|r|r|r|}
\hline \multicolumn{7}{|c|}{ SNI: Public sector offices and education } \\
\hline Variable & \multicolumn{1}{|c|}{ Unit } & Obs. & Mean & \multicolumn{1}{c|}{ CV } & Min & \multicolumn{1}{c|}{ Max } \\
\hline FTA & deliveries/week & 7 & 7.1 & $109 \%$ & 1 & 23 \\
\hline Intermediary & 1 if yes, 0 if not & 7 & 0.9 & $44 \%$ & 0 & 1 \\
\hline Interm. FTP & trips/week & 6 & 2.9 & $69 \%$ & 1 & 5 \\
\hline Employment & employees & 7 & 60.1 & $180 \%$ & 2 & 302 \\
\hline Area & $\mathrm{m} 2$ & 6 & $1,908.3$ & $159 \%$ & 150 & 8,000 \\
\hline Storage & $\mathrm{m} 2$ & 6 & 72.5 & $134 \%$ & 10 & 250 \\
\hline
\end{tabular}

Note: "Obs." denotes the number of observations; CV denotes coefficient of variation (i.e., mean/ standard deviation).

As shown, the mean values differ by commercial sector, and the coefficient of variance is high for most variables in every commercial sector except for food services. Retailers of perishable goods have by far the highest FTA (14.6 deliveries per week), followed by public sector offices and education establishments that attract half of perishable goods retailers' FTA (7.1 deliveries per week), and retailers of non-perishable goods and restaurants which attract a third of perishable goods retailers' FTA (5.4 and 5.1 respectively). Health care and other wellbeing services establishments have the lowest FTA (3.9 deliveries per week). FVA was only measured for retailers of perishable goods and resulted in an average of $72.7 \mathrm{~m} 3$ attracted every week.

The share of freight intermediary establishments also differs by commercial sector, with public sector offices and education, health care and other services, and retail of non-perishable goods having $90 \%, 80 \%$ and $60 \%$ of establishments both attracting and producing freight trips, respectively; while for food services and retail of perishable goods this share decreases to $30 \%$ and $50 \%$ respectively. However, from those establishments serving as freight intermediaries retailers of perishable goods have the highest mean of FTP (6.0 trips per week), followed by food services (3.4 trips per week), and retailers of non-perishable goods (3.0 trips per week).

In terms of employment and area, the public sector and education sector has the highest average of employees and area per establishment (60.1 employees and 1,908.3 m2), followed by health care and other wellbeing 
services (9.3 employees and $700.1 \mathrm{~m} 2)$, retail of perishable goods (5.4 employees and $620.6 \mathrm{~m} 2)$, food services (4.9 employees and $100.2 \mathrm{~m} 2$ ), and retail of non-perishable goods (2.9 employees and $164.2 \mathrm{~m} 2)$.

As shown, the allocation of space for storage varies across sectors, retailers have the highest average storage area with $147.1 \mathrm{~m} 2$ for perishable goods and 172.1 for non-perishable goods, using in average $42.1 \%$ and $33.4 \%$ of the area for storage, respectively. Public sector offices and education use $72.5 \mathrm{~m} 2$ for storage which represents only $6.7 \%$ of their area. Health care and other services establishments use $33.8 \mathrm{~m} 2$ for storage which represents $9.0 \%$ of their area; and food service establishments use in average only $29.3 \mathrm{~m} 2$ for storage, representing $37.5 \%$ of the establishment area.

To gain insight on other behavioral factors that affect FTA, some receivers were asked about their ordering/stockholding policy and who purchases the delivery service. The results are summarized in Table 4.

Table 4: Ordering/ stockholding policy and delivery service

\begin{tabular}{|c|c|c|c|c|c|c|c|c|c|c|c|c|c|c|}
\hline \multirow{3}{*}{ Commercial sector } & \multicolumn{7}{|c|}{ Ordering/ stockholding policy } & \multicolumn{7}{|c|}{ Who purchases the delivery service? } \\
\hline & \multicolumn{2}{|c|}{ Not known } & \multicolumn{2}{|c|}{ No } & \multicolumn{2}{|c|}{ Yes } & \multirow{2}{*}{$\begin{array}{c}\text { Total } \\
\mathrm{n} \\
\end{array}$} & \multicolumn{2}{|c|}{ Receiver } & \multicolumn{2}{|c|}{ Vendor } & \multicolumn{2}{|c|}{ Both occur } & \multirow{2}{*}{\begin{tabular}{|c|} 
Total \\
$\mathrm{n}$ \\
\end{tabular}} \\
\hline & $\mathrm{n}$ & $\%$ & $\mathrm{n}$ & $\%$ & $\mathrm{n}$ & $\%$ & & $\mathrm{n}$ & $\%$ & $\mathrm{n}$ & $\%$ & $\mathrm{n}$ & $\%$ & \\
\hline Retail perishable & 5 & $13 \%$ & 25 & $66 \%$ & 8 & $21 \%$ & 38 & 9 & $21 \%$ & 15 & $36 \%$ & 18 & $43 \%$ & 42 \\
\hline Retail non-perishable & 4 & $22 \%$ & 10 & $56 \%$ & 4 & $22 \%$ & 18 & 5 & $42 \%$ & 3 & $25 \%$ & 4 & $33 \%$ & 12 \\
\hline Food services & 1 & $13 \%$ & 7 & $88 \%$ & 0 & $0 \%$ & 8 & 2 & $25 \%$ & 2 & $25 \%$ & 4 & $50 \%$ & 8 \\
\hline Health care and other & 1 & $17 \%$ & 5 & $83 \%$ & 0 & $0 \%$ & 6 & 1 & $25 \%$ & 1 & $25 \%$ & 2 & $50 \%$ & 4 \\
\hline Public sector and education & 1 & $17 \%$ & 5 & $83 \%$ & 0 & $0 \%$ & 6 & 2 & $29 \%$ & 2 & $29 \%$ & 3 & $43 \%$ & 7 \\
\hline \begin{tabular}{|l} 
Total \\
\end{tabular} & 12 & $16 \%$ & 52 & $68 \%$ & 12 & $16 \%$ & 76 & 19 & $26 \%$ & 23 & $32 \%$ & 31 & $42 \%$ & 73 \\
\hline
\end{tabular}

Although the amount of data is not sufficient to draw conclusive results, the data show that most of the establishments surveyed do not have a clear ordering/ stockholding policy in place. In some cases, respondents said they did not know because the ordering/ stockholding policy was centralized. In the cases where respondents acknowledged a policy, common elements in the responses include that every item needs to be always available in the store, fresh products should always be available, storage space utilization should be maximized, first in first out policy, high storage for products traveling long distances, the shelves of the store are the stock, and cooled space limits stock. It is noteworthy that the share of establishments with an ordering/ stockholding policy acknowledge by the retailers is about $20 \%$, while for the other sectors the policy is either not clear, or there is no policy. In terms of who purchases the delivery service, for $42 \%$ of the establishments both receivers and vendors are responsible for purchasing a part of the delivery services, for $32 \%$ of them vendors are responsible, and for $26 \%$ receivers are responsible. A set of Pearson's correlation tests revealed no specific patterns or correlation between who purchases transport services and the number of employees in the establishment.

Another interesting result is the share of FTG by different vehicle class and industry sector. 
Table 5: Share of vehicle class per commercial sector

\begin{tabular}{|l|r|r|r|r|}
\hline \multicolumn{1}{|c|}{ Commercial sector } & Trucks & $\begin{array}{c}\text { Vans and } \\
\text { light vehicles }\end{array}$ & $\begin{array}{c}\text { Passenger } \\
\text { cars }\end{array}$ & \multicolumn{1}{c|}{$\begin{array}{c}\text { Bicycle/ } \\
\text { walking }\end{array}$} \\
\hline Retail perishable & $79.2 \%$ & $15.5 \%$ & $5.2 \%$ & $0.1 \%$ \\
\hline Retail non-perishable & $67.8 \%$ & $24.2 \%$ & $8.0 \%$ & $0.0 \%$ \\
\hline Food services & $61.2 \%$ & $5.9 \%$ & $29.3 \%$ & $3.6 \%$ \\
\hline Public sector and education & $41.1 \%$ & $38.4 \%$ & $20.5 \%$ & $0.0 \%$ \\
\hline Health care and other & $24.0 \%$ & $68.0 \%$ & $2.0 \%$ & $6.0 \%$ \\
\hline Total & $70.8 \%$ & $18.5 \%$ & $9.8 \%$ & $0.8 \%$ \\
\hline
\end{tabular}

As shown in Table 5, most of freight trips in Gothenburg are made by trucks (70.8\%), followed by vans and light vehicles (18.5\%) and passenger cars $(9.8 \%)$, and only a minor share of freight trips are made by bicycle and/or walking $(0.8 \%)$. These numbers are in line with findings from traffic counts in some areas of the city, see [41]. The results also show large variations of the shares across sectors. The share of trucks ranges from $79.2 \%$ for retail perishable establishments to only $24.0 \%$ for health care and other services. In the case of vans and light vehicles, the share ranges from $68.0 \%$ for health care and other services to $5.9 \%$ for food services. For food services, the share of passenger cars, bicycle and walking freight trips is larger than for the other sectors with $29.3 \%$ and $3.6 \%$, respectively.

In the case of FWA, the frequency histogram in Figure 1 shows the distribution across different sectors. The figure shows the share of establishments for each level of FWA within each sector.

\section{Figure 1: Freight weight attraction per commercial sector}

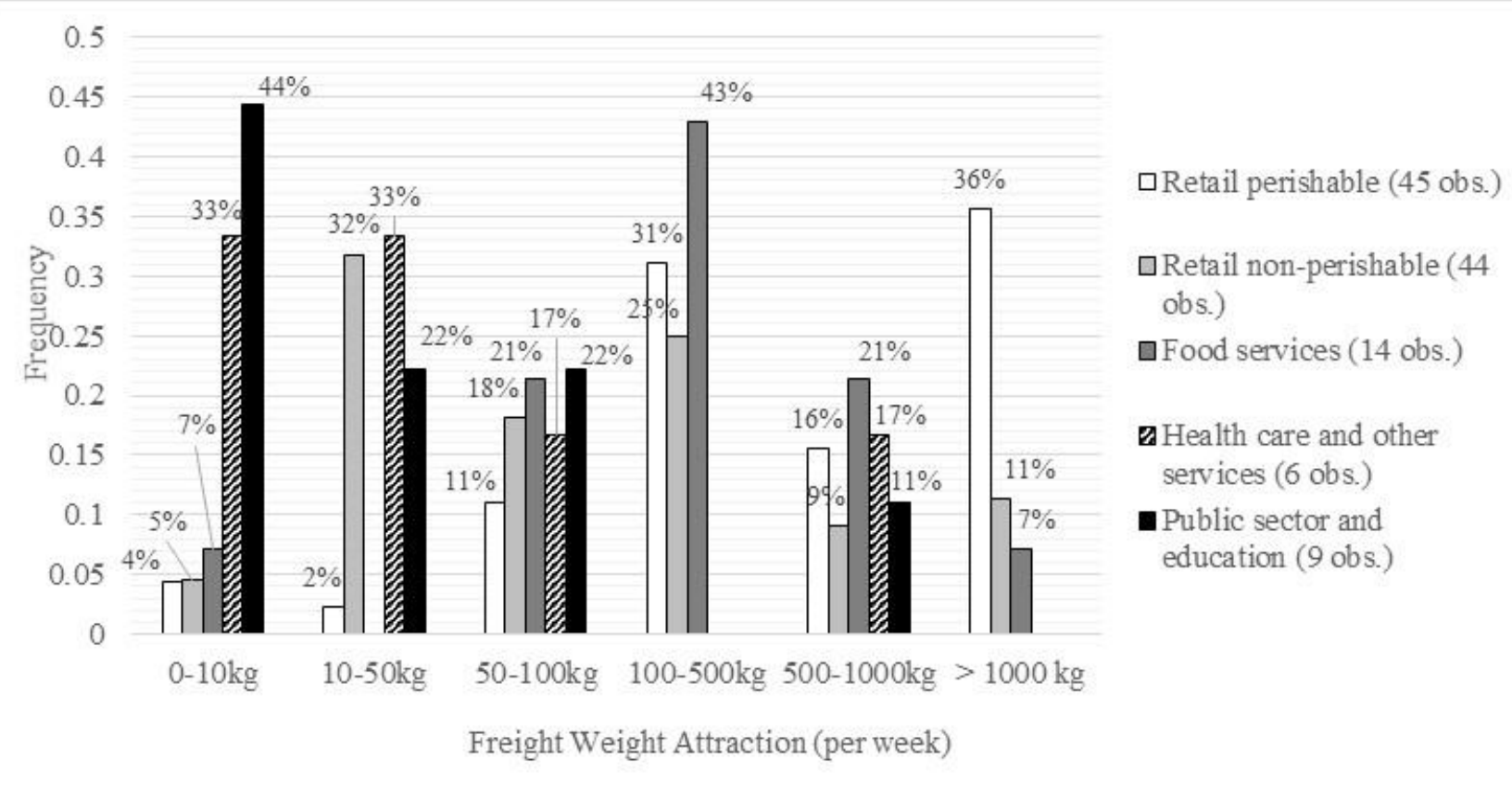

Note: Percentages on the label represent the share of establishments for each level of FWA within the sector.

As shown, retailers of perishable goods tend to attract the largest quantities of freight, with $83 \%$ of them attracting more than $100 \mathrm{~kg}$ per week. For the food service sector, about $75 \%$ attract more than $100 \mathrm{~kg}$ per week. In the case of retailers of non-perishable goods, about $45 \%$ attract more than $100 \mathrm{~kg}$, while for health care and 
other services, and public sector and education the vast majority attracts less than $100 \mathrm{~kg}$ (about $83 \%$ for both sectors).

As a complement to the FWA per sector, it is interesting to study the unit used for deliveries even though the number of observations per sector and delivery unit is very limited in some cases. Figure 2 shows the share of establishments within each sector receiving each delivery unit. The delivery units include pallets or rolling cages, parcel deliveries, and other delivery units (e.g., flowers, baskets, bags, single items).

Figure 2: Delivery units per commercial sector

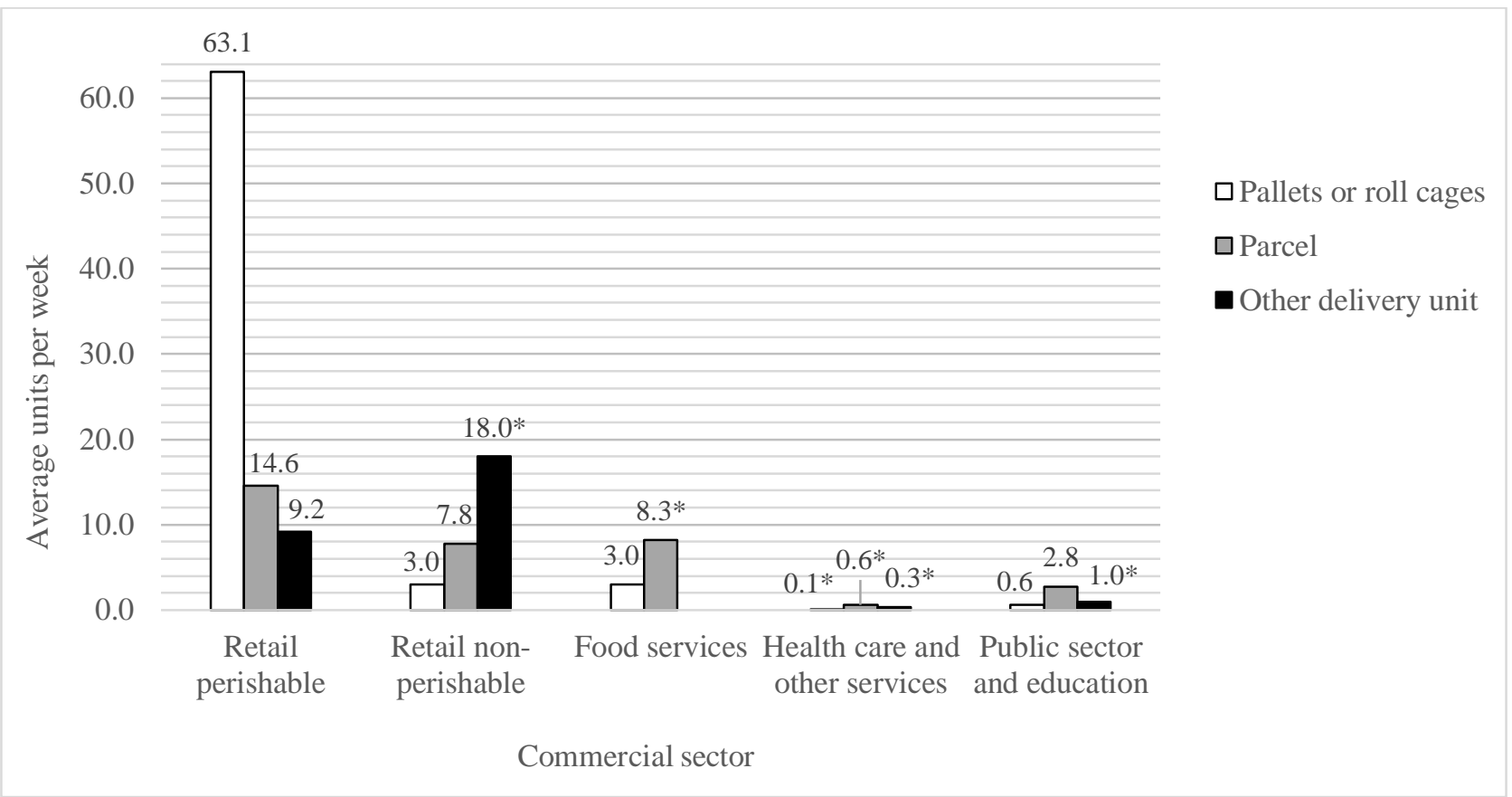

Note: The averages with (*) should be carefully considered because they correspond to averages of less than 5 observations. This histogram is based on 94 observations: 44 for retailers of perishable goods, 18 for retailers of nonperishable goods, 8 for food service, 4 for health care and other wellbeing services, and 7 for public sector and education.

Every establishment - independent from its commercial sector-receives deliveries in the form of a pallet or a rolling cage, even though in some cases the frequency is very low. Retailers of perishable goods receive by far the largest amount of pallets or roller cages, followed by retail of non-perishable goods and food services. The amount of parcel deliveries presents less variance across sectors.

\subsection{Modeling results}

The modeling efforts resulted into the pooled data models of type (a) presented in Table 6 and the models of type $(b)$ stratified by commercial segment and presented in Table 8 . Area and employment attributes cannot be included in the same model since they are highly correlated (correlation>0.6). Including both will lead to imprecise parameters because the calibration data do not provide information on partial effects of each attribute when the other is hold constant. The table also displays the t-statistics for each variable, the number of observations, the measures of goodness-of-fit for the model $\left(\mathrm{R}^{2}\right.$ and RMSE for FTA, and Pseudo $\mathrm{R}^{2}$ and $\log$ likelihood for FWA), and the threshold parameters for FWA. Table 6 shows the parameters for the FTA and 
FWA models that use either employment or area and commercial sector as variables. The parameters for FTA are estimated using a robust linear regression analysis, and FWA's are estimated using an order logit model.

Table 6: Pooled data FTA and FWA models

\begin{tabular}{|c|c|c|c|c|c|c|c|c|}
\hline \multirow{3}{*}{ Variables } & \multicolumn{4}{|c|}{ FTA (Y: trips per week) } & \multicolumn{4}{|c|}{ FWA (Z: ordinal variable) } \\
\hline & \multicolumn{2}{|c|}{ Employment } & \multicolumn{2}{|c|}{ Area } & \multicolumn{2}{|c|}{ Employment } & \multicolumn{2}{|c|}{ Area } \\
\hline & Param. & t-stat & Param. & $\mathrm{t}$-stat & Param. & t-stat & Param. & t-stat \\
\hline Intercept & 1.23 & $(1.32)$ & 3.94 & $(6.08)$ & 3.66 & $(13.72)$ & 3.55 & $(11.55)$ \\
\hline \multicolumn{9}{|l|}{ Comercial sector } \\
\hline Retail perishable & 5.68 & $(3.37)$ & 6.30 & $(2.97)$ & & & & \\
\hline Retail non-perishable & & & & & -1.41 & $(-3.80)$ & -1.65 & $(-4.26)$ \\
\hline Health care, and other services & & & & & -5.12 & $(-5.58)$ & -4.48 & $(-4.89)$ \\
\hline Public sector offices and education & & & & & -3.23 & $(-3.82)$ & -2.70 & $(-2.93)$ \\
\hline \multicolumn{9}{|l|}{ Business size } \\
\hline Employment & 1.42 & $(3.60)$ & & & 0.13 & $(4.45)$ & & \\
\hline Area & & & 0.76 & $(2.93)$ & & & 0.58 & $(4.82)$ \\
\hline \multicolumn{9}{|l|}{ Interaction terms } \\
\hline Emp*Food services & -0.78 & $(-2.28)$ & & & & & & \\
\hline Emp*Health care, and other services & -1.20 & $(-3.18)$ & & & & & & \\
\hline Emp*Public sector offices and education & -1.35 & $(-3.45)$ & & & -0.11 & $(-3.88)$ & & \\
\hline Area*Health care, and other services & & & -0.56 & $(-2.21)$ & & & -0.46 & $(-3.66)$ \\
\hline Area*Public sector offices and education & & & -0.53 & $(-6.08)$ & & & -0.53 & $(-4.32)$ \\
\hline \multicolumn{9}{|l|}{ Threshold parameters } \\
\hline$\mu(1)$ & \multicolumn{2}{|c|}{ n.a. } & \multicolumn{2}{|c|}{ n.a. } & 1.79 & $(7.62)$ & 1.85 & $(7.53)$ \\
\hline$\mu(2)$ & \multicolumn{2}{|c|}{ n.a. } & \multicolumn{2}{|c|}{ n.a. } & 2.80 & $(13.21)$ & 2.94 & $(13.05)$ \\
\hline$\mu(3)$ & \multicolumn{2}{|c|}{ n.a. } & \multicolumn{2}{|c|}{ n.a. } & 4.27 & (19.34) & 4.64 & $(18.70)$ \\
\hline$\mu(4)$ & \multicolumn{2}{|c|}{ n.a. } & \multicolumn{2}{|c|}{ n.a. } & 5.21 & $(19.09)$ & 5.92 & $(17.60)$ \\
\hline Observations & 18 & & 1. & 59 & \multicolumn{2}{|c|}{117} & \multicolumn{2}{|c|}{116} \\
\hline R2/ Pseudo R2 & \multicolumn{2}{|c|}{0.47} & \multicolumn{2}{|c|}{0.40} & \multirow{2}{*}{\multicolumn{2}{|c|}{0.15}} & \multicolumn{2}{|c|}{0.22} \\
\hline RMSE & \multirow{2}{*}{\multicolumn{2}{|c|}{10.13}} & \multirow{2}{*}{\multicolumn{2}{|c|}{11.38}} & \multirow{2}{*}{\multicolumn{2}{|c|}{-204.01}} & & \\
\hline Log likelihood & & & & & & & \multicolumn{2}{|c|}{-201.61} \\
\hline
\end{tabular}

Note: The parameter for area is in $100 \mathrm{~m}^{2}$. Pseudo $\mathrm{R}^{2}$ is the ratio between the log likelihood of the intercept model and the log likelihood of the full model.

The $\mathrm{R}^{2}$, the pseudo $\mathrm{R}^{2}$, and the RMSE reveal that while the employment model has a better goodness-of-fit for FTA, the area model has better goodness-of-fit for FWA. For FTA, the employment model shows that a typical retailer of perishable goods attracts a base of 6.91 every week while an establishment in other sectors attract a base of 1.23 trips every week, plus a number of trips that depends on the number of employees working in it. The effect of the number of employees on FTA is larger for retailers (1.42 extra trips/employee), followed by food services (0.64 extra trips/employee), and health care and other services ( 0.22 extra trips/employee). The unitary effect of the number of employees on the public sector is almost null (only 0.07 extra trips/employee). These relationships can be summarized in the following equation:

$$
F T A=1.23+5.68 \delta_{R P}+1.42 E-1.35\left(\delta_{P S} E\right)-1.20\left(\delta_{H C} E\right)-0.78\left(\delta_{F S} E\right)
$$

Where,

FTA: Freight trip attraction (in deliveries per week)

$E$ : Number of employees in a typical day 
$\delta_{R P}:$ A binary variable denoting if the establishment belongs to the retail perishable sector: 1 if the establishment belongs to the sector, 0 if not.

$\delta_{F S}$ : A binary variable denoting if the establishment belongs to the food services sector: 1 if the establishment belongs to the sector, 0 if not.

$\delta_{H C}$ : A binary variable denoting if the establishment belongs to the health care and other services sector:

1 if the establishment belongs to the sector, 0 if not.

$\delta_{P S}$ : A binary variable denoting if the establishment belongs to the public sector and education: 1 if the establishment belongs to the sector, 0 if not.

The area model shows that a typical establishment in the retail of non-perishable goods, in the food services sector, in the health care and other services, or the public sector and education attracts a base of 3.94 trips per week; while an establishment in the retail of perishable goods attracts a base of 10.24 trips per week. The effect of area on FTA is the same for retail and food services $\left(0.76\right.$ extra trips $\left./ 100 \mathrm{~m}^{2}\right)$, while for the health care and other wellbeing services and the public sector and education this effect is smaller $\left(0.20\right.$ extra trips $/ 100 \mathrm{~m}^{2}$ and 0.23 extra trips $/ 100 \mathrm{~m}^{2}$ respectively). These relationships can be summarized in the following equation:

$$
F T A=3.94+6.30 \gamma_{R P}+0.76 A-0.56\left(\gamma_{H C} A\right)-0.53\left(\gamma_{P S} A\right)
$$

Where,

$A$ : Area of the establishment (m2)

In the case of the FWA, the employment model shows that a typical establishment in in the retail of nonperishable goods, the health care and other services sector and in the public sector tends to attract less freight than one in the food services or in the retail of perishable goods. As expected, a higher number of employees increases the probability of a higher FWA. However, in the case of the public sector the unitary effect of the number of employees is lower than for the other sectors. The utility function can be expressed as:

$$
U=3.66-5.12 \gamma_{H C}-3.23 \gamma_{P S}-1.41 \gamma_{R N}+0.13 \mathrm{E}-0.11\left(\gamma_{P S} E\right)
$$

The FWA area model shows analogous results. The main differences are that the FWA of an establishment in the public sector does not increase with the area, and the unitary effect of area is lower for the health care and other services than for the other sectors. The utility function can be expressed as:

$$
U=3.55-4.48 \gamma_{H C}-2.70 \gamma_{P S}-1.65 \gamma_{R N}+0.58 \mathrm{~A}-0.53\left(\gamma_{P S} A\right)-0.46\left(\gamma_{H C} A\right)
$$

To apply these models, equations (9) and (10) should be replaced in the block of equations (5) to obtain the probabilities for each level of FWA, and the output should be used in (6) to compute the expected level of FWA.

A Brant test on the FWA models show that the specification would benefit from having an employment coefficient that varies across the different levels of FWA. A generalized order logit was tested to allow this feature, but the lack of observations and the resulting degrees of freedom prevent to have statistically significant parameters. This type of models and further enhancements will be the subject of further research as they could improve the performance of FWA models.

The results for the FTP discrete-continuous models are summarized in Table 7. The top of the table shows the results for the discrete models that identifies establishments that are more likely to be intermediaries; while the bottom shows the parameter to estimate FTP for those establishments that are intermediaries. 
Table 7: Pooled data discrete-continuous FTP models

\begin{tabular}{|c|c|c|c|c|c|c|}
\hline \multirow{3}{*}{ Variables } & \multicolumn{6}{|c|}{ FTP (Y: trips per week) } \\
\hline & \multicolumn{2}{|c|}{ Employment } & \multicolumn{2}{|c|}{ Area } & \multicolumn{2}{|c|}{ Combined } \\
\hline & Param. & t-stat & Param. & t-stat & Param. & t-stat \\
\hline \multicolumn{7}{|l|}{ Discrete model to identify intermediaries } \\
\hline Intercept & -0.79 & $(-3.49)$ & -0.77 & $(-2.54)$ & -0.79 & $(-3.49)$ \\
\hline \multicolumn{7}{|l|}{ Comercial sector } \\
\hline Retail non-perishable & & & 1.19 & $(2.99)$ & & \\
\hline Food services & & & 1.29 & $(2.70)$ & & \\
\hline Health care, and other services & & & 3.55 & $(2.07)$ & & \\
\hline Public sector offices and education & 1.82 & $(1.94)$ & & & 1.82 & $(1.94)$ \\
\hline \multicolumn{7}{|l|}{ Business size- Interaction terms } \\
\hline Emp*Retail non-perishable & 0.38 & $(3.20)$ & & & 0.38 & $(3.20)$ \\
\hline Emp*Food services & 0.18 & $(3.18)$ & & & 0.18 & $(3.18)$ \\
\hline Emp*Health care, and other services & -0.07 & $(-2.23)$ & & & -0.07 & $(-2.23)$ \\
\hline Emp*Public sector offices and education & 0.24 & $(2.33)$ & & & 0.24 & $(2.33)$ \\
\hline Area*Health care, and other services & & & -2.10 & $(-2.07)$ & & \\
\hline Area*Public sector offices and education & & & 0.76 & $(1.75)$ & & \\
\hline Pseudo R2 & 0. & 11 & & 09 & & 11 \\
\hline Log likelihood & -11 & 1.62 & & 14 & -11 & 1.62 \\
\hline \multicolumn{7}{|c|}{ Regression model to estimate FTP (trips/ week) } \\
\hline Intercept & 3.18 & $(5.04)$ & 4.50 & $(4.99)$ & 4.50 & $(4.99)$ \\
\hline \multicolumn{7}{|l|}{ Comercial sector } \\
\hline Retail non-perishable & & & -4.02 & $(-3.35)$ & -4.02 & $(-3.35)$ \\
\hline Health care, and other services & & & -2.78 & $(-2.18)$ & -2.78 & $(-2.18)$ \\
\hline \multicolumn{7}{|l|}{ Business size- Interaction terms } \\
\hline Emp*Retail perishable & 0.38 & $(6.80)$ & & & & \\
\hline Area*Retail non-perishable & & & 1.60 & $(2.58)$ & 1.60 & $(2.58)$ \\
\hline \multirow{2}{*}{$\begin{array}{l}\text { Adjusted R2 } \\
\text { RMSE } \\
\end{array}$} & \multicolumn{2}{|c|}{0.08} & \multicolumn{2}{|c|}{0.21} & \multicolumn{2}{|c|}{0.21} \\
\hline & \multicolumn{2}{|c|}{5.78} & \multicolumn{2}{|c|}{5.59} & \multicolumn{2}{|c|}{5.59} \\
\hline Observations & \multicolumn{2}{|c|}{89} & \multicolumn{2}{|c|}{84} & \multicolumn{2}{|c|}{84} \\
\hline
\end{tabular}

Note: The parameter for area is in $100 \mathrm{~m}^{2}$. Pseudo $\mathrm{R}^{2}$ is the ratio between the log likelihood of the intercept model and the log likelihood of the full model.

As shown, the Pseudo $\mathrm{R}^{2}$ shows that the employment model to identify intermediaries has a better goodnessof-fit than the area model; while the adjusted $\mathrm{R}^{2}$ shows that the area model has a better goodness-of-fit to estimate FTP. As a result the best models uses area and commercial sector to estimate the probability of an establishment being an intermediary, and uses number of employees and commercial sector to estimate FTP for those establishments that are intermediaries. The combined model shows that a typical establishment in the public sector and education is more likely to be an intermediary than for the other sectors; and a higher number of employees increases the probability of being an intermediary for the food services, the public sector and education, and the retail of non-perishable goods sectors. For the health care and other services a higher number of employees decreases the probability of being an intermediary. The utility function can be expressed as:

$$
U=-0.79-1.82 \gamma_{P S}-0.07\left(\gamma_{H C} E\right)+0.18\left(\gamma_{F S} E\right)+0.24\left(\gamma_{P S} E\right)+0.38\left(\gamma_{R N} E\right)
$$

For the second part of the model, a typical intermediary establishment in the retail of perishable goods, in the food services, in the public sector and education sectors produces 4.50 trips per week; while a typical intermediary establishment in the health care and other services sector produces 1.72 trips per week. In the case 
of retailers of non-perishable goods, a typical intermediary produces a base of 0.48 trips per week plus an extra 1.60 weekly trips per $100 \mathrm{~m}^{2}$. These relationships can be summarized in the following equation:

$$
F T A=4.50-4.02 \gamma_{R N}-2.78 \gamma_{H C}+1.60\left(\gamma_{R N} A\right)
$$

As an alternative, FTA, FTP and FVA models can use a specification of the type $(b)$ described in the methodology, in which the observations are stratified by commercial segment and either the number of employees or the area are used as explanatory variables. The health care and other services sector, and the public sector and education sector were excluded of this analysis because of the low number of observations. The results are presented in Table 8.

Table 8: Models per commercial sector

\begin{tabular}{|c|c|c|c|c|c|c|c|c|c|c|}
\hline \multirow{2}{*}{ Comercial sector } & \multicolumn{5}{|c|}{ Employment models } & \multicolumn{5}{|c|}{ Area models } \\
\hline & Obs. & Const. & Emp. & $\mathrm{R} 2$ & RMSE & Obs. & Const. & Area & $\mathrm{R} 2$ & RMSE \\
\hline \multicolumn{11}{|c|}{ Freight trip attraction models } \\
\hline Retail perishable & 54 & $\begin{array}{c}6.90 \\
(4.20)\end{array}$ & $\begin{array}{c}1.42 \\
(3.33)\end{array}$ & 0.42 & 16.89 & 50 & $\begin{array}{l}10.34 \\
(5.30)\end{array}$ & $\begin{array}{c}0.74 \\
(2.89)\end{array}$ & 0.35 & 18.53 \\
\hline Retail non-perishable & 70 & - & $\begin{array}{c}1.70 \\
(5.40)\end{array}$ & 0.53 & 5.66 & 63 & $\begin{array}{c}2.40 \\
(3.12)\end{array}$ & $\begin{array}{c}1.47 \\
(2.72)\end{array}$ & 0.26 & 6.13 \\
\hline Food services & 43 & $\begin{array}{c}2.85 \\
(2.52) \\
\end{array}$ & $\begin{array}{c}0.46 \\
(2.12) \\
\end{array}$ & 0.19 & 4.32 & 30 & $\begin{array}{c}5.12 \\
(7.10) \\
\end{array}$ & - & n.a. & 4.73 \\
\hline \multicolumn{11}{|c|}{ Freight volume attraction models } \\
\hline Retail perishable & 32 & - & $\begin{array}{l}22.70 \\
(4.10) \\
\end{array}$ & 0.73 & 106.87 & 32 & - & $\begin{array}{r}15.67 \\
(3.44) \\
\end{array}$ & 0.75 & 102.04 \\
\hline \multicolumn{11}{|c|}{ Freight trip production models for intermediaries } \\
\hline Retail perishable & 16 & $\begin{array}{c}3.91 \\
(2.95)\end{array}$ & $\begin{array}{c}0.35 \\
(6.35) \\
\end{array}$ & 0.35 & 4.83 & 16 & - & $\begin{array}{c}0.27 \\
(2.83)\end{array}$ & 0.15 & 7.81 \\
\hline Retail non-perishable & 40 & - & $\begin{array}{c}1.07 \\
(2.96)\end{array}$ & 0.33 & 6.10 & 38 & - & $\begin{array}{c}1.65 \\
(3.01)\end{array}$ & 0.45 & 5.66 \\
\hline Food services & 22 & \begin{tabular}{|c|}
3.35 \\
$(2.65)$ \\
\end{tabular} & - & n.a. & 5.92 & 22 & $\begin{array}{c}3.35 \\
(2.65) \\
\end{array}$ & - & n.a. & 5.92 \\
\hline
\end{tabular}

Notes: Const. denotes the intercept of the model, Emp. denotes the parameter for number of employees, the parameter for area is in $100 \mathrm{~m} 2$; $\mathrm{t}$-stat are displayed between parentheses under each parameter

As shown, the models display a fair goodness-of-fit with R2 varying between 0.15 (for retail perishable FTP) and 0.75 (for retail perishable FVA); and the RMSE varying between 4.32 (for the food services FTA) and 18.53 (for retail of perishable goods FTA). Based on the RMSE and the $\mathrm{R}^{2}$, the employment models have better goodness-of-fit for FTA and for retail of perishable goods FTP; while the area models lead to better goodnessof-fit for retail of perishable goods FVA and FTP.

The FTA model for retail non-perishable is a rate of 1.70 trips per employee, implying that establishment with few employees have very low FTA. The FTA model for retail perishable and food services have both a constant and an employment rate, implying that they attract a base of 6.90 and 2.85 weekly trips, respectively, and an additional 1.42 and 0.46 trips per employee. In the case of retail perishable and non-perishable goods, the area models suggest that an establishment attracts 10.34 and 2.40 weekly trips, respectively, and an additional 0.74 and 1.47 weekly trips per every additional $100 \mathrm{~m}^{2}$ of area. 
Similarly as for FTA, the FTP model for retail non-perishable is a rate of 1.07 trips per employee, or 1.65 trip per $100 \mathrm{~m}^{2}$, implying that establishment with few employees have very low FTP. The FTP model for retail perishable has both a constant and an employment rate, suggesting that a typical establishment produces a base of 3.91 trip per week, and an addition 0.35 trips per employee. For the food services FTP is constant, thus a typical establishment produces 3.35 trips every week independent from its business size. In essence, the models are in general conceptually similar to the ones of type $(a)$ but the parameters present some variations.

In the case of FVA, the $\mathrm{R}^{2}$ shows a good goodness-of-fit of the models for both employment $(0.73)$ and area (0.75). Moreover, the models show that freight volumes attracted by retailers of perishable goods can be computed either as a rate of employees $\left(22.90 \mathrm{~m}^{3}\right.$ per employee $)$ or as a rate of area $\left(15.64 \mathrm{~m}^{3}\right.$ per $\left.100 \mathrm{~m}^{2}\right)$.

\subsection{Comparison between FTG estimates and traffic counts}

This section presents the comparison between FTG estimates and freight traffic observed in the Domkyrkan Area, a commercial district in the city center of Gothenburg that encompasses fragments of ZIP codes 411 14, $41115,41116$.

The traffic counts data were collected by the Traffic Office of the City of Gothenburg in 2013 using a cordonbased system in Domkyrkan area. The data includes two days of counts (a Wednesday and a Thursday) of all freight commercial vehicles entering the study zone between 6:30 AM to 6:00 PM. Overall, 219 freight commercial vehicles entered the zone on Wednesday and 170 on Thursday, giving an average of 195 freight commercial vehicles per day entering the study zone, excluding waste collection, construction and maintenance, and service commercial vehicles. It is noteworthy that this number does not include personal vehicles used for deliveries, which account for about $24 \%$ of deliveries according to the FTG data collected in the study area, see [41]. A summary of the traffic shares per time-of-the-day and sector is presented in Table 9. A complete analysis of the traffic data is provided by Dixit [41].

Table 9: Summary of traffic results from the cordon-based study for Domkyrkan area, Gothenburg

\begin{tabular}{|l|r|r|r|r|r|r|r|r|}
\hline Entry Time & 3PL & $\begin{array}{c}\text { Express } \\
\text { courier } \\
\text { and post }\end{array}$ & HoReCa & Retail & $\begin{array}{c}\text { Construction } \\
\text { \& } \\
\text { Maintinance }\end{array}$ & Services & $\begin{array}{c}\text { Waste } \\
\text { Collection }\end{array}$ & Total \\
\hline $6: 30-7: 30$ & $1.3 \%$ & $0.3 \%$ & $1.6 \%$ & $0.7 \%$ & $2.6 \%$ & $0.7 \%$ & $5.2 \%$ & $12.5 \%$ \\
\hline $7: 30-8: 30$ & $1.3 \%$ & $1.6 \%$ & $1.6 \%$ & $0.0 \%$ & $4.6 \%$ & $2.0 \%$ & $2.6 \%$ & $13.8 \%$ \\
\hline $8: 30-9: 30$ & $6.9 \%$ & $1.3 \%$ & $1.3 \%$ & $1.6 \%$ & $1.3 \%$ & $2.0 \%$ & $0.3 \%$ & $14.8 \%$ \\
\hline $9: 30-10: 30$ & $4.9 \%$ & $0.3 \%$ & $3.3 \%$ & $3.6 \%$ & $0.7 \%$ & $2.0 \%$ & $0.7 \%$ & $15.4 \%$ \\
\hline $10: 30-11: 30$ & $4.6 \%$ & $0.7 \%$ & $1.6 \%$ & $1.0 \%$ & $2.0 \%$ & $1.3 \%$ & $0.3 \%$ & $11.5 \%$ \\
\hline $11: 30-12: 30$ & $2.6 \%$ & $0.7 \%$ & $0.3 \%$ & $0.7 \%$ & $1.0 \%$ & $0.3 \%$ & $0.0 \%$ & $5.6 \%$ \\
\hline $12: 30-13: 30$ & $4.9 \%$ & $1.3 \%$ & $1.6 \%$ & $0.7 \%$ & $1.0 \%$ & $0.3 \%$ & $0.0 \%$ & $9.8 \%$ \\
\hline $13: 30-14: 30$ & $1.6 \%$ & $0.7 \%$ & $1.0 \%$ & $0.7 \%$ & $1.3 \%$ & $1.0 \%$ & $0.0 \%$ & $6.2 \%$ \\
\hline $14: 30-15: 30$ & $1.0 \%$ & $0.3 \%$ & $0.7 \%$ & $0.3 \%$ & $0.3 \%$ & $0.7 \%$ & $0.0 \%$ & $3.3 \%$ \\
\hline $15: 30-16: 30$ & $2.0 \%$ & $0.7 \%$ & $0.0 \%$ & $1.0 \%$ & $0.7 \%$ & $1.0 \%$ & $0.0 \%$ & $5.2 \%$ \\
\hline $16: 30-18: 00$ & $0.0 \%$ & $0.3 \%$ & $0.3 \%$ & $0.3 \%$ & $0.7 \%$ & $0.3 \%$ & $0.0 \%$ & $2.0 \%$ \\
\hline Total & $31.1 \%$ & $8.2 \%$ & $13.4 \%$ & $10.5 \%$ & $16.1 \%$ & $11.5 \%$ & $9.2 \%$ & $100.0 \%$ \\
\hline
\end{tabular}

Source: [41].

To compute the FTG estimates, the FTG models introduced in this paper are applied to all the establishments in the Domkyrkan study area, using the number of establishments and employment data per commercial sector 
from the Swedish Central Office of Statistics (SCB) [35] and the public database Allabolag.se [42]. The results from the application of the FTG to the area is presented in Table 10.

Table 10: Traffic estimations for a typical day in Domkyrkan area (Gothenburg) from FTG models

\begin{tabular}{|l|r|r|r|r|r|r|}
\hline \multicolumn{1}{|c|}{ Commercial sector } & $\begin{array}{c}\text { Establish- } \\
\text { ments }\end{array}$ & $\begin{array}{c}\text { FTA } \\
\text { (pooled) }\end{array}$ & $\begin{array}{c}\text { Interme- } \\
\text { diaries }\end{array}$ & FTP & FTG & FWA \\
\hline Accommodation and Food & 42 & 22 & 16 & 21 & 43 & $3,483.8$ \\
\hline Health care services & 32 & 8 & 1 & 17 & 25 & 102.2 \\
\hline Public services and education & 6 & 1 & 4 & 3 & 5 & 68.0 \\
\hline Retail non-perishable & 87 & 113 & 23 & 46 & 159 & $4,947.9$ \\
\hline Retail perishable & 4 & 6 & 1 & 2 & 8 & 361.6 \\
\hline Total & 171 & 149 & 45 & 90 & 239 & $8,963.6$ \\
\hline
\end{tabular}

The results in Table 10 show that most of the FTG in this commercial district is a consequence of FTA, and it is generated by establishments in the retail of non-perishable goods and accommodation and food sectors which are predominant in the zone of study. The results also show that FTG models estimates are on average 22.5\% larger than the observed commercial freight vehicles traffic from the cordon-based survey, which falls under the range of acceptable errors for traffic studies (i.e., +/-25\%) [43]. A closer look to the nature of the data and the collection methods suggests that the difference in the estimations can be explained by the following facts: $(i)$ freight traffic counts only consider vehicles with commercial plates, while FTG also considers about $20 \%$ additional deliveries made with personal vehicles, (ii) some freight vehicles deliver to more than one establishment in the same block, and (iii) the variance of traffic across days, which based on the traffic counts study can be around $30 \%$. Another potential reason for the difference in the estimations is that the traffic counts data were collected in 2013, while the FTG data were collected between 2014 and 2015.

In essence, the comparison between FTG estimates and the traffic counts shows that despite some difference in the numbers, FTG models provide a good estimation of freight traffic. Moreover, the availability of FTG models overcomes the need for additional cordon-based data collection, and enables the application of the models to assess public sector interventions (e.g., urban consolidation centers, freight demand management initiatives, land use ordinance changes) as well as to forecast local traffic for future urban developments.

\section{CONCLUSIONS}

This paper provides the background on the state-of-the-art of Freight Generation (FG) and Freight Trip Generation (FTG) models, identifies common factors used to study commercial establishments' FG and FTG behavior, and highlights a concerning lack of FG models. A closer look to FG models shows that the main challenge is to collect reliable data. To close this gap, the author collect FG data using in situ measurements for Freight Volume Attraction (FVA) and inquiring about Freight Weight Attraction (FWA) using numerical intervals. The data collection exercise took place in the City of Gothenburg and also includes questions on FTG, employment, area and commercial activity, among others. The data collection requires special attention. In particular, as the respondents are not experts in urban freight and receiving deliveries is often not their main task, the meticulous work from the interviewers is crucial to minimize the risk of overlooked deliveries and errors in the response.

The analysis of the data shows that retailers of perishable goods tend to have large storage space, and very high FWA and Freight Trip Attraction (FTA). Retailers of non-perishable sector tend to have large storage space, medium to low FWA, but medium to high FTA. In the case of the food sector, establishments tend to 
have very reduced storage space, medium to high FTA and high FA. Establishments in the public and education sectors have medium storage areas, low FWA, but medium to high FTA; and establishments in the health care, and other services tend to have reduced storage space, low to medium FTA and low FA. The inquiry on ordering/ stockholding policy shows that there is no clear policy from the receivers point of view, which suggests an opportunity for initiatives that seek to reduce the impacts of urban traffic by inducing changes in receivers' ordering behavior, see [8].

The model development shows a number of possibilities to quantify FVA, FWA, FTA and FTP using regression analyses and discrete choice models. The modeling results show that a typical establishment attracts a base number of trips ranging from 1.23 to 10.24 trips/week, plus an extra number of trips that depends on the business size - that can be as high as 1.42 extra trips/employee or 0.76 extra trips/100m². In the case of FVA, the models show that retailers of perishable goods attract a volume directly proportional to business size (22.90 $\mathrm{m}^{3} / \mathrm{employee}$ or $15.64 \mathrm{~m} 3 / 100 \mathrm{~m}^{3}$ ).

In the case of FTP, the modeling results show that a typical establishment in the public sector and education is more likely to be an intermediary than for the other sectors; and a higher number of employees increases the probability of a being an intermediary for the food services, the public sector and education, and the retail of non-perishable goods sectors. For the health care and other services a higher number of employees decreases the probability of being an intermediary. Moreover, a typical intermediary establishment in the retail of perishable goods, in the food services, in the public sector and education sectors produces 4.50 trips per week; while a typical intermediary establishment in the health care and other services sector produces 1.72 trips per week. In the case of retailers of non-perishable goods, a typical intermediary produces a base of 0.48 trips per week plus an extra 1.60 weekly trips per $100 \mathrm{~m}^{2}$. Although FTP currently represents a small share of FTG, it is important to start studying FTP of urban commercial establishments as the increasing amount of residential deliveries coupled with omni-channel inventory optimization strategies could increase FTP of urban establishments in the near future.

As shown in this paper, the theory of discrete choice models allows the estimation of FWA as an ordinal variable (i.e., $Z_{n}=1$ if FWA is between 0 and $10 \mathrm{~kg}, Z_{n}=2$ if FWA is between 11 and $50 \mathrm{~kg}, Z_{n}=3$ if FWA is between 51 and $100 \mathrm{~kg}, Z_{n}=4$ if FWA is between 101 and $500 \mathrm{~kg}, Z_{n}=5$ if FWA is between 501 and 1,000 kg, and $Z_{n}=6$ if FWA is more than 1,000 kg per week). The probabilistic model shows that an increase in business size always lead to an increase in the expected FWA. The application of this model produces estimates of the intensity of FWA.

In general, the modeling results show an acceptable goodness-of-fit for the FG and FTG models; and the comparison between FTG estimates and traffic counts from a cordon-based survey revealed that the application of FTG models provides a good estimation of the freight traffic entering the zone of study. Along with the encouraging results, there are some limitations to be addressed and some opportunities for further research. The scope of this study does not include establishments typical of sub-urban areas (e.g., manufacturing, wholesaling), a complementary study on these sectors will provide better insight of the relationship between shippers and receivers, and contribute to have a better overall picture of FTG that could be used for modeling trips distribution. The collection of urban freight data requires a continue effort to study the evolution of FG/FTG patterns and to obtain larger datasets that can be used for more sophisticated models. For instance, a larger dataset would allow to estimate a generalized ordered logit as suggested by the Brant test and to explore the definition of the FWA ordinal variable. The use of intervals allowed to collect data on FWA and to estimate models, further efforts should focus on refining the definition of intervals to allow respondents to provide an answer to the question and also provide a good level of detail for FWA models. This paper focused on variables 
and models that are ready to use for planning purposes and policy formulation, a new modeling effort could focus on less practice-oriented models that explore empirical relationships between exploratory variables (sales, storage space, location, type of firm, land value).

In essence, the data collected and the different types of models introduced are an important contribution to the literature and a valuable tool for planners and practitioners. The availability of FG/FTG models allows to understand urban establishments' freight needs, estimate freight traffic in existing urban environment, assess the feasibility and benefits of public sector interventions (e.g., urban consolidation centers, freight demand management initiatives, land use ordinance changes), and forecast local traffic for future urban developments. This information is bound to enhance public authorities' decision-making outcome to facilitate efficient freight distribution in a highly urbanized world.

\section{ACKNOWLEDGEMENTS}

The author would like to acknowledge the support from the Volvo Research and Educational Foundations (VREF) that funded the Urban Freight Platform (UFP) through its Future Urban Transport research program, and Vinnova, Sweden's Innovation Agency that founded the DenCity Project. The author would also like to acknowledge the contributions from Sofia Guldbrand, Linda Johansson, Lovisa Westblom, Leeza Malik and Saubhagya Dixit whose efforts in data collection and in the design of the survey instrument were crucial for the development of this research.

\section{REFERENCES}

[1] United Nations, "World Urbanization Prospects," United Nations, New York, USA2014.

[2] The World Bank. (2015, September 9th). Urban Development. Available: http://www.worldbank.org/en/topic/urbandevelopment/overview

[3] Smart Growth Network and ICMA, "Getting to Smart Growth: 100 Policies for Implementation," U.S. Environmental Protection Agency. 2002.

[4] J. Holguín-Veras, J. Amaya-Leal, J. Wojtowicz, M. Jaller, C. González-Calderón, I. Sánchez-Díaz, et $a l .$, "Interactive Planning Guide: Improving Freight System Performance in Metropolitan Areas," Transportation Research Board, Washington, D.C. 2015.

[5] J. Holguín-Veras, M. Jaller, L. Destro, X. Ban, C. Lawson, and H. S. Levinson, "Freight Generation, Freight Trip Generation, and the Perils of Using Constant Trip Rates," Transportation Research Record: Journal of the Transportation Research Board, vol. 2224, pp. 68-81, 2011.

[6] J. Holguín-Veras, M. Jaller, I. Sanchez-Díaz, J. M. Wojtowicz, S. Campbell, H. S. Levinson, et al., "NCHRP Report 739 / NCFRP Report 19: Freight Trip Generation and Land Use," Transportation Research Board of the National Academies, Washington D.C. NCHRP Report 739/NCFRP Report 19, 2012.

[7] J. D. Ortúzar and L. G. Willumsen, Modelling Transport, 4th ed. New York: John Wiley and Sons, 2011.

[8] J. Holguín-Veras and I. Sánchez-Díaz, "Freight Demand Management and the Potential of ReceiverLed Consolidation Programs," Transportation Research A, vol. 84, pp. 109-130, 2016.

[9] Institute of Transportation Engineers ITE, Trip Generation: An ITE Informational Report, 8th ed. Washington, D.C.: Institute of Transportation Engineers, 2008.

[10] T. R. Ramakrishna and P. Balbach, "Truck Trip Generation Characteristics of Nonresidential Land Uses," ITE Journal, vol. 64, pp. 43-47, July 19941994.

[11] D. Beagan, M. Fischer, and A. Kuppam, "Quick Response Freight Manual II," Department of Transportation. Federal Highway Administration, Washington, D.C.September 20072007. 
[12] Federal Highway Administration, "Guidebook on Statewide Travel Forecasting," University of Wisconsin-Milwaukee and the Wisconsin Department of Transportation, Milwaukee, Wisconsin1999.

[13] Cambridge Systematics Inc., "Quick Response Freight Manual. Final Report of the Federal Highway Administration," Cambridge Systematics, IncSept. 1996.

[14] R. S. Bartlett and W. H. Newton, "Goods Vehicle Trip Generation and Attraction by Industrial and Commercial Premises," Transport and Road Research Laboratory 1059, 1982.

[15] M. H. E. Iding, W. J. Meester, and L. A. Tavasszy, "Freight Trip Generation by Firms," presented at the 42nd European Congress of the European Regional Science Association, Dortmund, Germany, 2002.

[16] J. L. Routhier and F. Toilier, "FRETURB V3, a Policy Oriented Software Tool for Modelling Urban Goods Movement," in 11th World Conference on Transport Research, Berkeley, CA, 2007, p. 35.

[17] K. Kawamura, H. S. Shin, S. McNeil, and L. Ogard, "Business and Site Specific Trip Generation Methodology For Truck Trips," 2008.

[18] C. Bastida and J. Holguín-Veras, "Freight Generation Models: Comparative Analysis of Regression Models and Multiple Classification Analysis," Transportation Research Record, vol. 2097, pp. 51-61, 2009.

[19] S. Campbell, M. Jaller, I. Sanchez-Diaz, J. Holguín-Veras, and C. Lawson, "Comparison Between Industrial Classification Systems in Freight Trip Generation (FTG) Modeling," presented at the 91st Annual Meeting of the Transportation Research Board, Washington, D.C 2012.

[20] C. Lawson, J. Holguín-Veras, I. Sánchez-Díaz, M. Jaller, S. Campbell, and E. Powers, "Estimated Generation of Freight Trips Based on Land Use," Transportation Research Record: Journal of the Transportation Research Board, vol. 2269, pp. 65-72, 2012.

[21] J. Holguín-Veras, I. Sánchez-Díaz, C. Lawson, M. Jaller, S. Campbell, H. S. Levinson, et al., "Transferability of Freight Trip Generation Models," Transport Research Record, vol. 2379, pp. 1-8, 2013.

[22] M. Jaller, I. Sanchez, J. Holguín-Veras, and C. Lawson, "Area Based Freight Trip Generation Models," 2013.

[23] I. Sánchez-Díaz, J. Holguín-Veras, and X. Wang, "An Exploratory Analysis of Spatial Effects on Freight Trip Attraction," Transportation, vol. 43, pp. 177-196, 2014/12/06 2016.

[24] M. Jaller, I. Sánchez-Díaz, and J. Holguín-Veras, "Identifying Freight Intermediaries: Implications for Freight Trip Generation Modeling," Transportation Research Record: Journal of Transportation Research Board, vol. 2478, pp. 48-56, 2015.

[25] J. González-Feliu, M. G. Cedillo-Campo, and J. L. García-Alcaraz, "An emission model as an alternative to OD matrix in urban goods transport modelling," Dyna, vol. 81, pp. 249-256, 2014.

[26] A. Alho and J. de Abreu e Silva, "Freight-Trip Generation Model: Predicting Urban Freight Weekly Parking Demand from Retail Establishment Characteristics," Transportation Research Record: Journal of the Transportation Research Board, pp. 45-54, 2014.

[27] R. Ducret and J. Gonzalez-Feliu, "Connecting demand-estimation model and spatial modeling for urban freight: first attempt and research implications," in City Logistics IX, Canary Islands, Spain, 2015.

[28] J. Gonzalez-Feliu, I. Sánchez-Díaz, and C. Ambrosini, "Aggregation level, variability and linear hypotheses for urban delivery generation models," presented at the 95th Annual Meeting of the Transportation Research Board, Washington, D.C., 2016.

[29] J. Waliszewski, D. Ahanotu, and M. Fischer, "Comparison of Commodity Flow Forecasting Techniques in Montana," Transportation Research Record: Journal of the Transportation Research Board, vol. 1870, pp. 1-9, 2004.

[30] J. Sorratini and R. Smith, "Development of a Statewide Truck Trip Forecasting Model Based on Commodity Flows and Input-Output Coefficients," Transportation Research Record: Journal of the Transportation Research Board, vol. 1707, pp. 49-55, 2000.

[31] F. Russo and A. Comi, "Urban Freight Movement: A Quantity Attraction Model," 2002. 
[32] L. A. Tavasszy, M. van de Vlist, C. Ruijgrok, and J. Van de Rest, "Scenario-wise Analysis of Transport and Logistic Systems with a SMILE," in WCTR Conference, Antwerp, 1998.

[33] J. Oosterhaven, T. Knaap, C. J. Ruijgrok, and L. A. Tavasszy, "On the Development of RAEM: The Dutch Spatial General Equilibrium Model and its First Application," in 41th European Regional Science Association Conference, Zagreb, 2001.

[34] S. Guldbrand, L. Johansson, and L. Westblom, "Estimating freight deliveries in urban environments," Master of Science Technology Management and Economics, Chalmers University of Technology, Gothenburg, SE, 2015.

[35] Statistiska Centralbyrån. (2007, October 15th). SNI 2007. Available: http://www.sni2007.scb.se/snisokeng.asp

[36] J. Holguín-Veras, C. Wang, I. Sánchez-Díaz, S. Campbell, S. D. Hodge, M. Jaller, et al., "Fostering Unassisted Off-Hour Deliveries: The Role of Incentives," Tranportation Research Part A: Policy and Practice, vol. (in print), 2015.

[37] J. Allen, S. Anderson, M. Browne, and P. Jones, "A framework for considering policies to encourage sustainable urban freight traffic and goods/service flows," Summary Report. Transport Studies Group, University of Westminister, UK, 2000.

[38] F. Belotti, P. Deb, W. G. Manning, and E. C. Norton, "twopm: Two-part models," Stata Journal, vol. 15, pp. 3-20, 2015.

[39] T. A. Domencich and D. McFadden, Urban Travel Demand: A Behavioural Analysis. Amsterdam: Noth-Holland, 1975.

[40] D. A. Freedman, "On the so-called "Huber sandwich estimator" and "robust standard errors"," The American Statistician, vol. 60, 2006.

[41] S. Dixit, "Characteristics and unsustainable impacts of urban freight in Gothenburg and Delhi," Master of Technology in Transportation Engineering, Department of Civil Engineering, Indian Institute of Technology, Delhi, India, 2015.

[42] UC Group. (2015, February 10th). Allabolag.se. Available: http://www.allabolag.se/start

[43] W. A. Martin and N. A. McGuckin, "NCHRP 365: Travel estimation techniques for urban planning," Washington, D.C.1998. 